\title{
PENGENALAN PROGRAM PERAWATAN PESAWAT TERBANG BAGI SISWA SMA IT BAITUSSALAM PRAMBANAN
}

\author{
Fajar Khanif Rahmawati \\ Program Studi Teknik Dirgantara \\ Sekolah Tinggi Teknologi Adisutjipto \\ J1. Janti Blok R Lanud Adisutjipto Yogyakarta \\ fajar.khanif@gmail.com
}

\begin{abstract}
Every person has the opportunity to get the knowledge. Age or generational constraints do not prevent a person from sharing or acquiring knowledge. The earlier a person is able to gain a knowledge, it will increase the insight and level of the ability to each person. It will also could be positive value if it is applied to senior high school students. They need much of knowledge that could be used in every decision they will take to pursue the next stage of education. Sharing knowledge that is basically beyond the curriculum learned in high school will greatly add new insights to students. The knowledge of the aviation in general scope and the role of aircraft maintenance programs in a particular scope are knowledge that certainly have not been taught in senior high school. The purpose of community service performed at SMA IT Baitussalam is to share information and knowledge about aviation in general scope and the role of aircraft maintenance in particular scope. It is hoped that through the implementation of this activity, it could increase the knowledge and insight of students and could be used as one of the provisions or references to continue the next level of education.
\end{abstract}

Keywords: knowledge, aviation, aircraft maintenance

\begin{abstract}
Abstrak
Ilmu pengetahuan sejatinya adalah milik setiap orang untuk dapat memperolehnya. Batasan usia ataupun generasi tidak menjadi penghalang seseorang untuk berbagi ataupun memperoleh ilmu pengetahuan. Semakin dini seseorang mampu memperoleh sebuah pengetahuan maka akan semakin menambah wawasan dan tingkat kemampuan dari orang tersebut. Hal ini pun akan menjadi nilai lebih jika diterapkan pada siswa SMA yang mana mereka memerlukan sumbangan banyak ilmu pengetahuan yang dapat dijadikan bekal dalam setiap keputusan yang akan mereka ambil untuk menempuh tahapan pendidikan selanjutnya. Berbagi ilmu pengetahuan yang pada dasarnya di luar kurikulum yang dipelajari di bangku SMA akan sangat menambah wawasan baru bagi siswa. Pengetahuan tentang dunia penerbangan pada umumnya, dan peranan program perawatan pada khususnya merupakan pengetahuan yang tentunya belum diajarkan di bangku SMA. Tujuan dari pengabdian masyarakat yang dilakukan di SMA IT Baitussalam adalah untuk berbagi informasi dan pengetahuan mengenai dunia penerbangan pada umumnya dan peranan perawatan pesawat terbang pada khususnya. Diharapkan melalui pelaksanaan kegiatan ini, dapat menambah pengetahuan dan wawasan siswa serta dapat dijadikan salah satu bekal atau referensi untuk melanjutkan ke jenjang pendidikan selanjutnya.
\end{abstract}

Kata Kunci: ilmu pengetahuan, penerbangan, perawatan pesawat terbang 


\section{Latar Belakang Masalah}

Ilmu pengetahuan selalu memiliki manfaat yang positif baik untuk yang berbagi ilmu ataupun yang memperoleh ilmu pengetahuan tersebut. Semakin bertambahnya pengetahuan seseorang akan semakin menambah wawasan, dengan semakin bertambah wawasan maka bahan pertimbangan untuk setiap langkah yang diambil akan semakin matang. Pengetahuan mengenai dunia penerbangan pada umumnya dan peranan perawatan pesawat terbang pada khususnya, tidaklah mudah untuk diakses kecuali dilakukan pada bidang konsentrasi yang spesifik pada ilmu tersebut.

Siswa yang duduk di bangku SMA, adalah siswa yang berada pada masa - masa transisi loncatan ilmu pengetahuan. Karena selain hanya dari ilmu pengetahuan yang diperoleh di bangku sokolah, mereka harus pula mencari ilmu pengetahuan yang lebih luas lagi untuk menambah wawasan serta untuk bekal dalam menentukan pendidikan pada tahap berikutnya. Pengenalan - pengenalan awal mengenai dunia penerbangan akan menambah khazanah pengetahuan yang dapat mereka miliki. Melalui pengenalan awal yang diberikan, siswa dapat lebih memperdalam pemahaman dengan diskusi ataupun membaca literatur yang terkait.

Oleh karena itu sangat penting untuk diselenggarakan kegiatan pengabdian masyarakat terhadap SMA IT Baitussalam dengan kegiatan berbagi informasi dan pengetahuan megenai dunia penerbangan pada umumnya dan perawatan pesawat terbang pada khususnya. Informasi dan pengetahun awal yang diberikan akan memberikan stimulus kepada siswa untuk menggali lebih dalam lagi, baik melalui diskusi dengan ahlinya ataupun dengan membaca literatur yang ada. Dengan tambahan bekal pengetahuan yang diberikan diharapkan dapat menambah referensi siswa jika ingin melanjutkan pendidikan ke tahap yang lebih tinggi. Jika pun bidang ilmu yang dipilih pada akhirnya bukan merupakan konsentrasi pada dunia penerbangan, akan tetapi tambahan ilmu pengetahuan yang diperoleh tetap dapat dimanfaatkan, karena sejatinya setiap ilmu pengetahuan selalu memberikan manfaat bagi kehidupan.

\section{Metodologi Penelitian}

Kegiatan yang dilaksanakan berupa pemberian materi melalui paparan atau presentasi diikuti dengan sesi tanya jawab, kemudian dilanjutkan dengan kunjungan ke laboratorium yaitu hangar pesawat dan shop perawatan pesawat terbang.

Pada sesi pertama, pelaksanaan pengabdian dilakukan di dalam ruang Adisutjipto dengan memberikan paparan atau presentasi terkait materi yang diberikan yaitu Pengenalan Program Perawatan Pesawat Terbang. Pada sesi ini diharapkan siswi dapat memperoleh pengetahuan awal mengenai program perawatan pesawat terbang. Selanjutnya pada sesi kedua, siswi diajak mengunjungi laboratorium termasuk hangar pesawat dan shop perawatan pesawat terbang. Pada sesi ini diharapkan dapat lebih memperdalam wawasan siswi terhadap materi yang telah diperoleh di dalam kelas karena siswa dalam melihat secara langsung kondisi pesawat atapun shop tempat perawatan pesawat terbang.

Dalam perencanaannya untuk mendukung terlaksananya kegiatan pengabdian masyarakat pada siswi SMA IT Baitussalam, pelaksana melakukan beberapa kegiatan, diantaranya koordinasi para pelaksana untuk menyiapkan tempat dan perlengkapan guna mendukung terlaksananya kegiatan, kemudian pelaksana melakukan koordinasi dengan para peserta yaitu SMA IT Baitussalam. Selanjutnya mempersiapkan modul materi yang akan disampaikan dengan rincian materi seperti yang terlihat pada Tabel 1. 
Tabel 1. Topik Materi Pada Modul [3][4]

\begin{tabular}{|c|l|}
\hline No. & \multicolumn{1}{|c|}{ Topik } \\
\hline 1. & Filosofi Perawatan Pesawat Terbang \\
\hline 2. & Sejarah Perawatan Pesawat Terbang \\
\hline 3. & Definisi dan Peranan Perawatan Pesawat Terbang \\
\hline 4. & Contoh - contoh Kasus \\
\hline
\end{tabular}

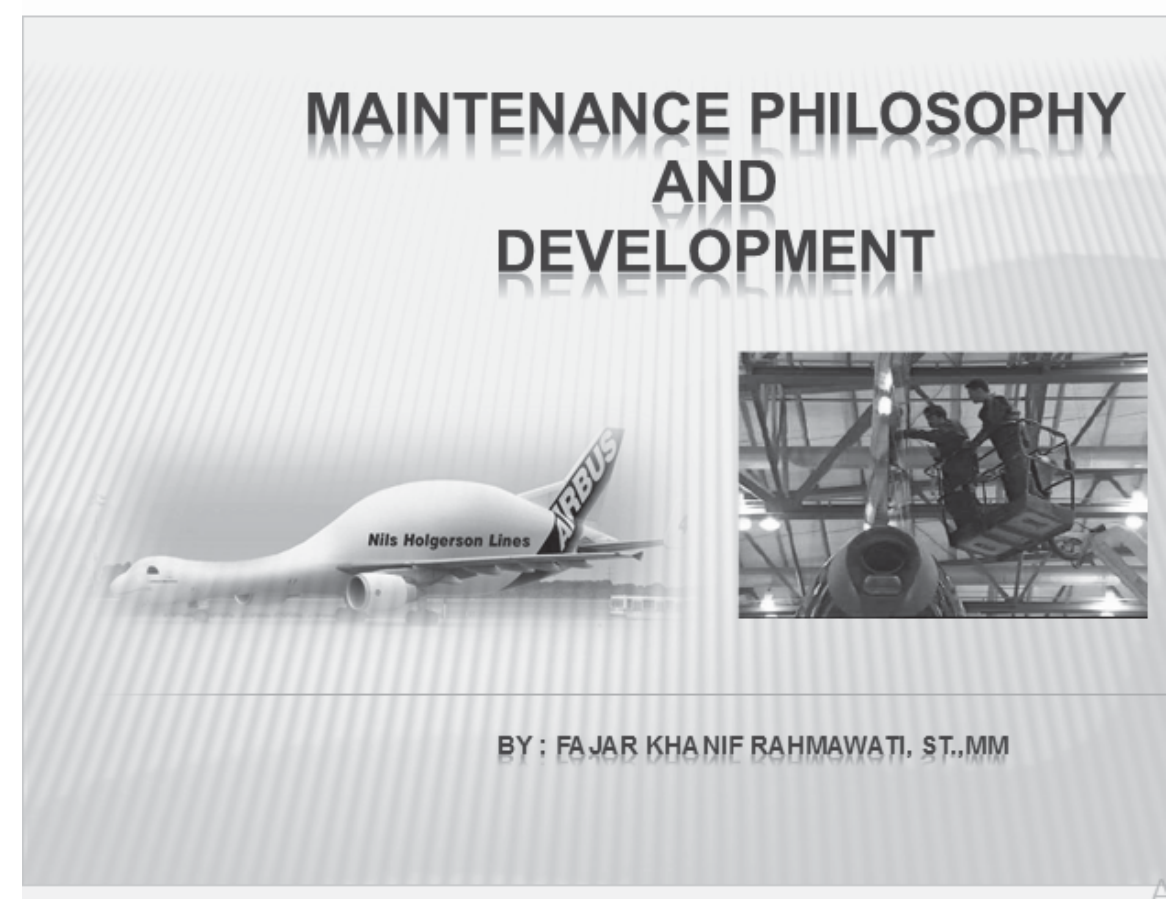

Gambar 1. Tampilan Cover Modul

\section{Hasil dan Pembahasan}

Pengabdian masyarakat yang diselenggarakan oleh Dosen Program Studi Teknik Dirgantara bagi siswa SMA IT Baitussalam Prambanan dilaksanakan di Sekolah Tinggi Teknologi Adisutjipto (STTA). Kegiatan ini berlangsung pada hari Sabtu, 28 April 2018 yang berlangsung pada pukul $08.00-15.00$. Pelaksana kegiatan terdiri dari sembilan dosen dengan memberikan topik masing - masing pada saat pemberian materi yang berlangsung di Ruang Adisutjipto Sekolah Tinggi Teknologi Adisutjipto (STTA) kemudian dilanjutkan pengenalan Laboratorium termasuk hangar pesawat dan shop perawatan pesawat terbang. 


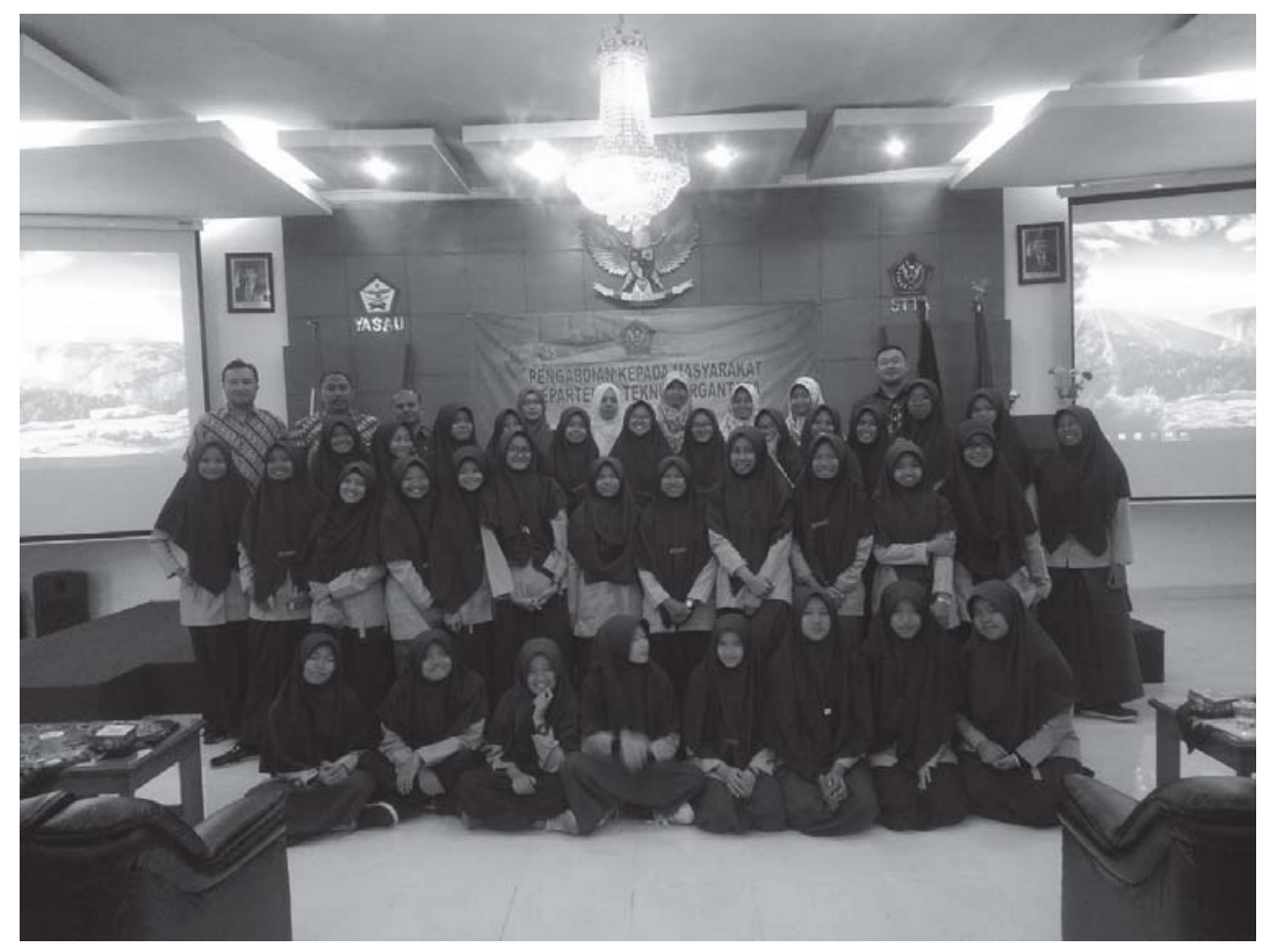

Gambar 2. Tim Pelaksana dan Peserta Pengabdian Kepada Masyarakat

Pada kegiatan pengabdian masyarakat ini diikuti oleh peserta dari siswi SMA IT Baitussalam yang terdiri dari 40 (empat puluh) siswa dan didampingin oleh 3 (tiga) guru. Pelaksanaan pengabdian masyarakat dibagi dalam dua sesi, yang pertama adalah sesi pemberian materi berupa paparan atau presentasi dari penyaji di dalam kelas terkait materi atau ilmu yang akan diberikan. Maka pada sesi ini materi mengenai pengenalan program perawatan pesawat diberikan kepada siswi SMA IT Baitussalam di dalam kelas kemudian dilanjutkan dengan tanya jawab dengan siswi SMA IT Baitussalam untuk mengetahui penguasaan dari materi yang telah diberikan. Pada sesi paparan, pemateri menjelaskan definisi maintenance menurut CASR 01 yaitu maintenance is the performance of tasks required to ensure the continuing airworthiness of an aircraft, including any one or combination of overhaul, inspection, replacement, defect rectification, and the embodiment of a modification or repair [1]. Pengertian maintenance penting untuk terlebih dahulu dijelaskan kepada siswa agar siswa dapat memahami bahwa perawatan pada pesawat terbang meliputi semua kegiatan yang dilakukan untuk menjaga keselamatan penerbangan dan kemudian siswa dapat lebih mudah memahami contoh contoh yang diberikan oleh pemateri. Setelah pengertian mengenai aircraft maintenance disampaikan kemudian pemateri memberikan contoh program perawatan yang diambil dari pesawat Cessna Grand Caravan 208B [2]. Melalui penjelasan pengertian dan contoh yang diberikan diharapkan dapat memberikan pemahaman dan gambaran nyata kepada siswa mengenai peranan pada pesawat terbang. 


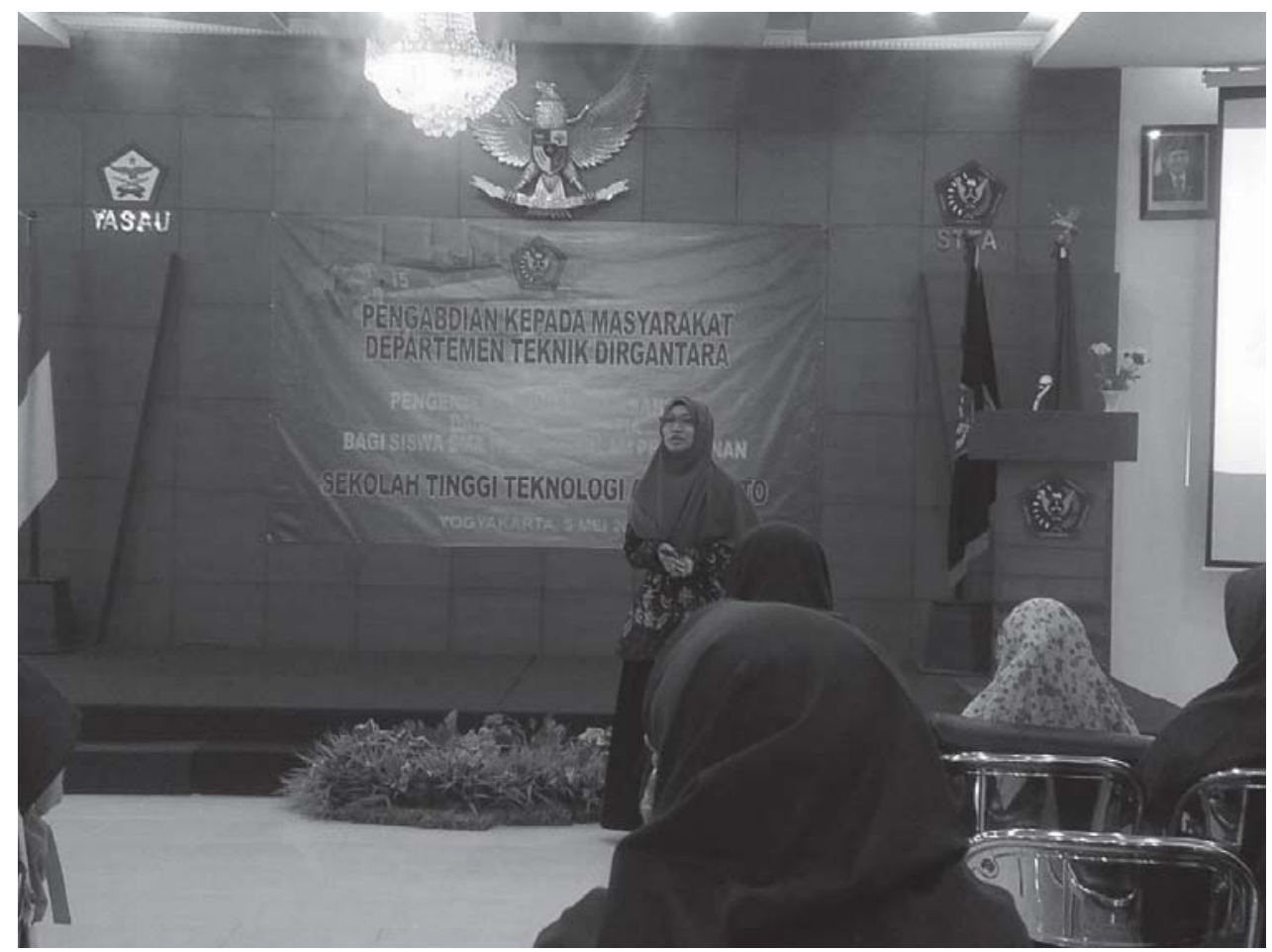

\section{Gambar 3. Kegiatan Pelaksanaan Pengabdian Masyarakat di Ruang Adisutjipto Sekolah Tinggi Teknologi Adsutjipto}

Setelah sesi pemberian materi berupa paparan atau presentasi di dalam kelas, dilanjutkan sesi yang kedua yaitu sesi kunjungan ke Laboratorium yang mana termasuk mengunjungi hangar tempat penyimpanan pesawat dan shop perawatan pesawat terbang, di mana di tempat tersebut merupakan tempat untuk pelaksanaan praktek secara langsung dari kegiatan pengajaran. Maka dengan kunjungan yang dilakukan oleh siswi SMA IT Baitussalam dapat semakin memperkuat pengetahuan yang diperoleh di dalam kelas pada sesi pertama, karena siswi dapat melihat secara langsung kondisi real di lapangan. 


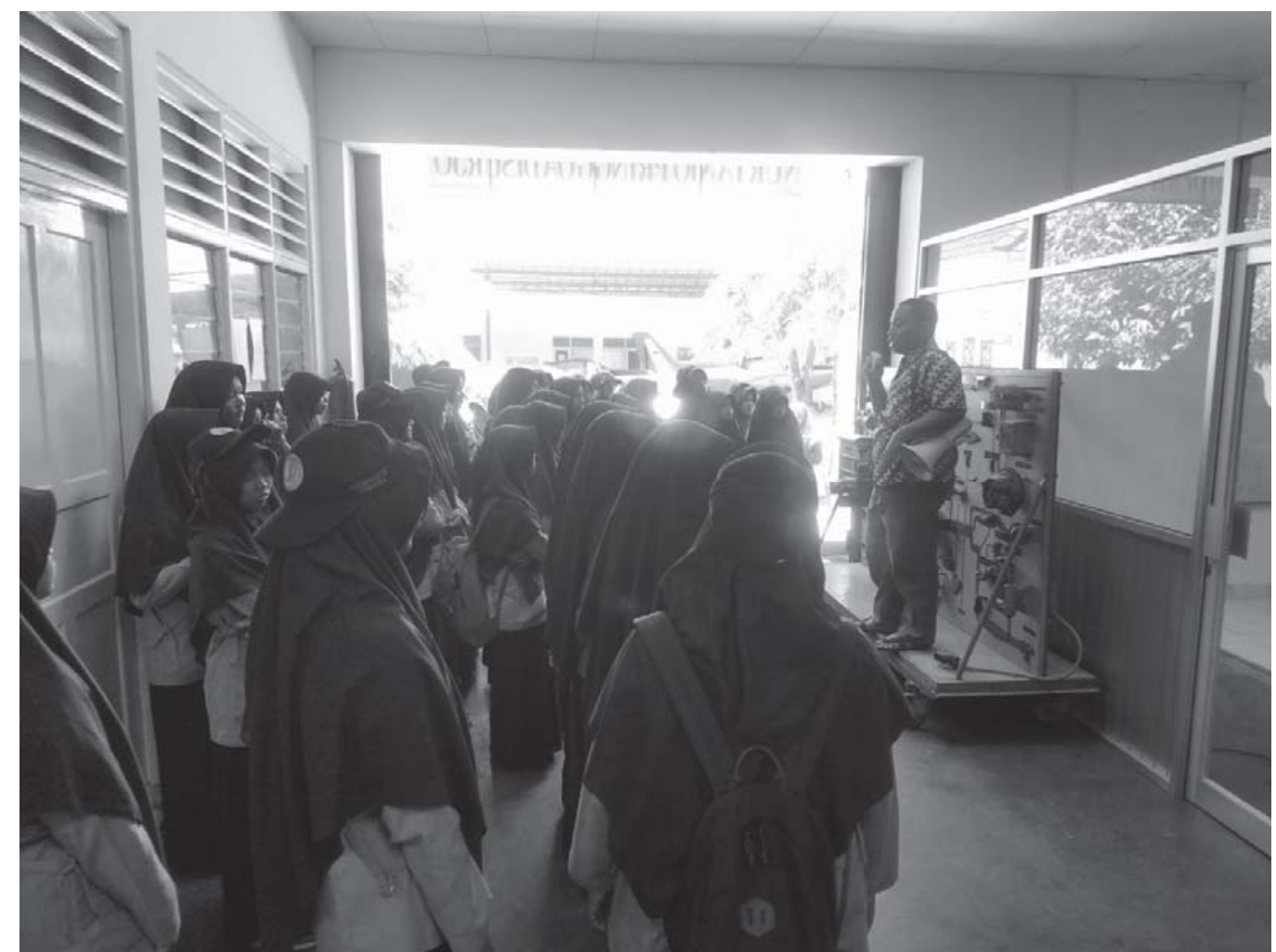

Gambar 4. Kegiatan Pengabdian Masyarakat saat Kunjungan ke Laboratorium

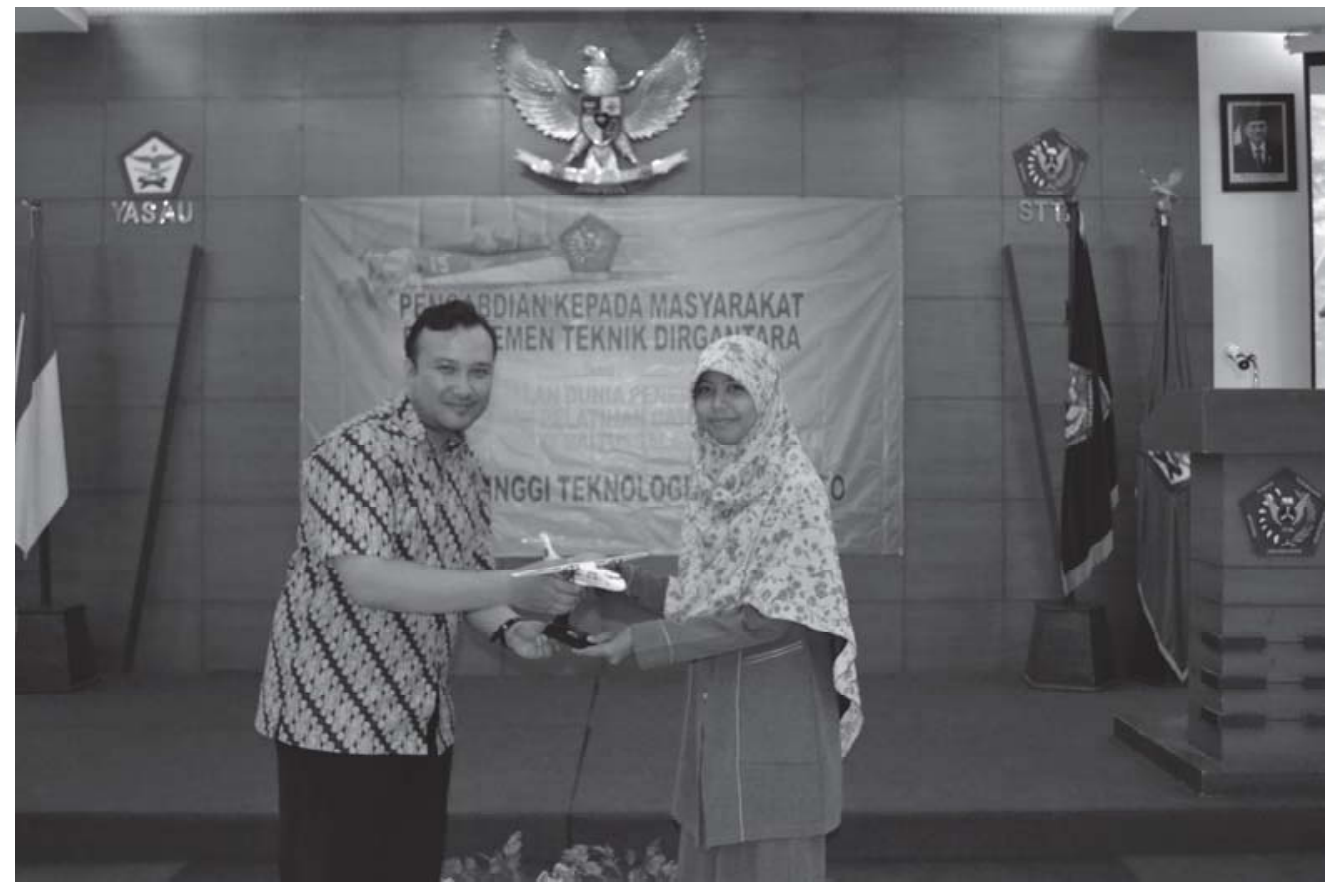

Gambar 5. Penutupan Kegiatan Pengabdian Kepada Masyarakat

Setelah pemberian materi di kelas dan kunjungan laboratorium selesai, penutupan acara dilakukan demo menerbangkan pesawat aeromodeling yang dibantu oleh UKM aeromodeling. Pada kegiatan ini siswi juga dapat ikut praktek langsung menerbangkan pesawat dari UKM aeromodeling. Pelaksanaan demo terbang yang dibantu oleh UKM aero modeling terdiri dari teknisi yang mempersiapkan pesawat untuk terbang dan juga pilot yang mengendalikan pesawat saat diterbangkan. Dengan demo yang dilaksanakan diharapkan semakin menambah pengetahuan siswa tentang dunia penerbangan pada 
umumnya dan peranan perawatan pada khususnya karena sebelum diterbangkan pesawat telah terlebih dahulu dipersiapkan oleh teknisi agar penerbangan bisa berjalan dengan lancar.

\section{Kesimpulan}

Kegiatan pengabdian kepada masyarakat berupa pemberian materi di kelas mengenai program perawatan pada pesawat terbang dapat memberikan pengenalan awal tentang peranan program perawatan pada pesawat bagi Siswa SMA IT Batussalam. Pengabdian masyarakat yang diselenggarakan oleh Dosen Program Studi Teknik Dirgantara STTA Yogyakarta mampu memberikan kontribusi positif terhadap peningkatan pengetahuan para siswa mengenai dunia penerbangan pada umumnya dan program perawatan pesawat pada khususnya. Untuk ke depannya perlu dikembangkan lagi dengan tidak hanya pemberian materi yang dilaksanakan di kelas tetapi juga dilengkapi dengan praktek, sehingga terwujud peningkatan keterampilan siswa dalam pengembangan ilmu pengetahuan yang dimiliki.

\section{Daftar Pustaka}

[1] Anonymous, 2006, Civil Aviation Safety Regulation (CASR) Part 1 revision 1, Kementrian Perhubungan, Jakarta

[2] Cessna Technical Publication, 2013, "Cessna Grand Caravan 208B Aircraft Maintenance Manual.01", USA.

[3] Edi Suwondo, 2017, Manajemen Perawatan Pesawat Terbang, ITB

[4] Kinnison A, Harry dan Siddiqui, T., 2004, Aviation Maintenance Manajemen 2nd Edition, The Mc Graw-Hill, New York.

[5] http://www.ilmuterbang.com//, diakses pada tanggal 05 April 2018 